\title{
A EA e os alunos com NEE: Atividades da Vida Diária (AVD), a água e sua utilização sustentável
}

\section{EA and students with SEN-Activities of Daily Living (ADL), water and their sustainable use}

Olga Santos ${ }^{1}$, Carla Gomes ${ }^{2}$ e Mário Oliveira ${ }^{1}$.1. Escola Superior de Educação e Ciências SociaisIPL/iACT/NIDE. 2. Escola Secundária de Ourém (Portugal)

\begin{abstract}
Resumo
O presente artigo tem como objetivo dar a conhecer atividades desenvolvidas na disciplina de Ciências da Natureza, do $6^{\circ}$ ano de escolaridade, com alunos com Necessidades Educativas Especiais (NEE), tendo subjacentes Atividades da Vida Diária (AVD) relacionadas com o consumo de água, visando a consciencialização para a importância deste recurso, bem como da necessidade da racionalização do seu consumo. A água potável é um bem cada vez mais escasso, sendo a sua utilização e governança sustentáveis, cada vez mais, um propósito que deverá envolver Toda a comunidade, o que implica incluir crianças/jovens com NEE, as quais poderão/deverão também contribuir para alcançar tais desígnios. Considerando a Escola uma instituição de ensino e aprendizagem essencialmente formal, onde o conhecimento do recurso água, a sua gestão e utilização sustentáveis são conteúdos curriculares de abordagem obrigatória para todos os alunos, foi elaborado um conjunto de atividades práticas alicerçadas nas AVD, permitindo dessa forma o envolvimento direto dos alunos com NEE nas mesmas, tornando-os cidadãos de pleno direito, mais conhecedores e, consequentemente, mais interventivos na comunidade e ambiente que integram.
\end{abstract}

\section{Astract}

The purpose of this article is to present activities developed in Natural Sciences discipline, of the 6th year of schooling, with students with special educational needs, with underlying daily life activities related to the consumption of water, aiming to raise awareness of the importance of this resource, as well as the need to rationalize its consumption. Potable water is an increasingly scarce resource, and its use and governance are increasingly sustainable, a purpose that should involve the whole community, which implies including children/young people who can/should also contribute to achieve such goals. Considering the School an essentially formal teaching and learning institution, where knowledge of the water resource, its sustainable management and use are mandatory curricular contents for all students, a set of practical activities based on the daily life activities were elaborated, thus allowing the direct involvement of all students in them, making them citizens with full rights, more knowledgeable and consequently more involved in the community and environment that they integrate.

\section{Palavras chave}

Educação Especial; Educação Ambiental; Inclusão; Atividades da Vida Diária.

\section{Key-words}

Special Education; Environmental Education; Inclusion; Activities of Daily Living. 


\section{Introdução}

A Educação Ambiental (EA) promove a aquisição de capacidades, comportamentos e atitudes imprescindíveis para manter o equilíbrio entre o Homem e o Ambiente no que tange aos seus recursos naturais limitados, como é exemplo a água. Urge, assim, sensibilizar todos os cidadãos do planeta para que os impactos negativos a este nível sejam minimizados. Quando referimos todos os cidadãos, incluímos os que são portadores de deficiência, que não devem ser esquecidos do cômputo das atividades veiculadas pela EA, com o objetivo de formar cidadãos informados e esclarecidos. A EA deve ter a preocupação de desenvolver atividades de acordo com o perfil de funcionalidade de cada um dos seus destinatários, almejando que cada cidadão possa dar o seu contributo, por mais elementar que seja.

A água potável, essencial à vida na Terra, é um bem cada vez mais escasso, sendo a sua utilização e governança sustentáveis, cada vez mais, um propósito que deverá envolver Toda a comunidade, o que implica incluir crianças/jovens com NEE, as quais poderão/deverão contribuir para alcançar tais desígnios.

Considerando a Escola uma instituição de ensino e aprendizagem essencialmente formal, onde o conhecimento do recurso água, a sua gestão e utilização sustentá- veis são conteúdos curriculares de abordagem obrigatória para todos os alunos, foi elaborado um conjunto de atividades práticas, promovendo uma abordagem educacional inovadora, alicerçadas nas Atividades da Vida Diária (AVD), permitindo, dessa forma, o envolvimento direto dos alunos com NEE nas mesmas, tornando-os cidadãos de pleno direito, mais conhecedores e, consequentemente, mais interventivos na comunidade e ambiente que integram.

O trabalho desenvolvido foi aplicado nas aulas da disciplina de Ciências Naturais (CN), tendo decorrendo no laboratório de $\mathrm{CN}$, envolvido alunos de uma turma de 6 . $^{\circ}$ ano de escolaridade, e resultante da frequência, pela docente, de uma ação de formação continua destinada a professores daquele ciclo de ensino. Dos alunos que compunham o grupo turma, cinco tinham NEE, sendo que três deles beneficiavam de Currículo Específico Individual (CEI). Dos alunos com CEI, apenas dois tinham contemplada a disciplina de $\mathrm{CN}$ no seu currículo, ainda que na atividade também tivesse participado uma aluna que não tinha esta disciplina contemplada no respetivo CEI. Relembramos que, "mais do que informações e conceitos, a escola se disponha a trabalhar com atitudes, com formação de valores e com mais ações práticas do que teóricas para que o aluno possa aprender a respeitar e praticar ações voltadas à conservação ambiental (Medeiros, et al, 2008). 
As atividades aplicadas integram-se no currículo de $\mathrm{CN}$ do 6 . $^{\circ}$ ano de escolaridade,

- no Domínio II - Agressões do meio e integridade do organismo, e

- no Subdomínio 2 - Higiene e problemas sociais.

- nas Metas curriculares:

18.4. Indicar alguns exemplos de diferentes tipos de poluição do ar exterior, da água e do solo.

18.5. Descrever as consequências da exposição a poluentes do ar interior e exterior, da água e do solo na saúde individual, nos seres vivos e no ambiente.

18.6. Enumerar medidas de controlo da poluição e da promoção de ambientes saudáveis.

Para os alunos com CEI, as metas foram simplificadas nos seguintes objetivos:

- Identificar tipos de poluição do ar, água e solo.

- Mencionar medidas de controlo da poluição.

Das atividades exploradas, a atividade, denominada "Consumo de água e os seus impactes", pretendeu sensibilizar os alu- nos para o desperdício de água e para a utilização mais eficiente e sustentável da mesma. Antes da exploração desta atividade pelos alunos, foi feita uma introdução à temática, visando simultaneamente motivá-los para o tema, tendo sido visionado e explorado um filme vídeo. Foi, posteriormente, efetuada a revisão dos conteúdos programáticos lecionados no $5 .^{\circ}$ ano sobre a disponibilidade de água doce no planeta.

Após esta introdução, foi feita a exploração da atividade 1, que apresentava várias questões-problema.

A Questão-problema I - O ser humano utiliza água para que fins?, foi resolvida individualmente, tendo sido as respostas registadas por escrito, como se pode verificar pela figura 1, e posteriormente discutidas em grupo. As repostas alcançadas pelos alunos, em grupo, foram sendo registadas no quadro branco, como se ilustra na figura 2. Os alunos com NEE resolveram a atividade com a ajuda da professora e dos colegas, tendo conseguido acompanhar, oralmente, a evolução da atividade e alcançar os seus objetivos, revelando dificuldades no tocante ao registo escrito das mesmas. Esta situação justifica a adequação dos materiais de registo como se poderá verificar adiante.

\section{Questão-problema I: O ser humano utiliza água para que fins?}

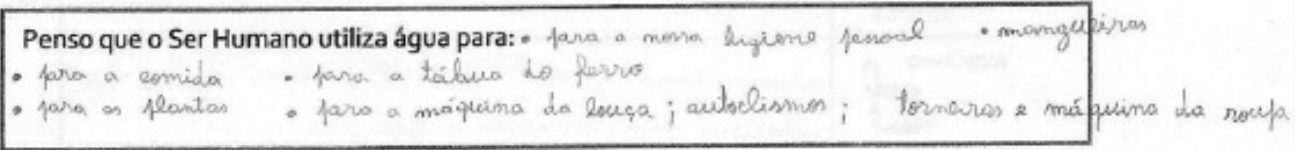

Figura 1: Resposta de aluno sem NEE 


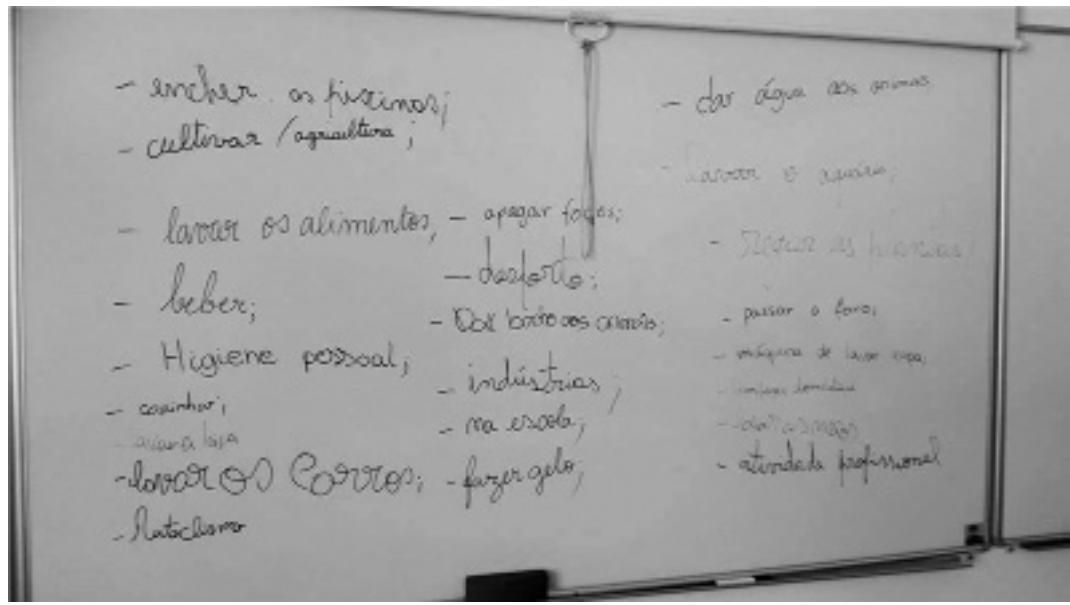

Figura 2:

As várias

respostas

da turma à

Questão-pro-

blema I -

O ser humano

utiliza água

para que fins?

Posteriormente, foi analisado um gráfico circular, apresentado ao lado, na figura 3, representativo da utilização da água no planeta, estimulando a discussão sobre as ideias dos alunos e procurando que se constituísse como uma síntese do que foi referido pelos mesmos.

A questão-problema II - Que quantidade de água gastas por dia?, foi explorada em conjunto com todos os alunos em contexto de sala de aula, optando-se por enviar as questões 2 e 3 como tarefa para realizar em casa, com a ajuda e sensibilização dos pais. Esta situação pode contribuir de

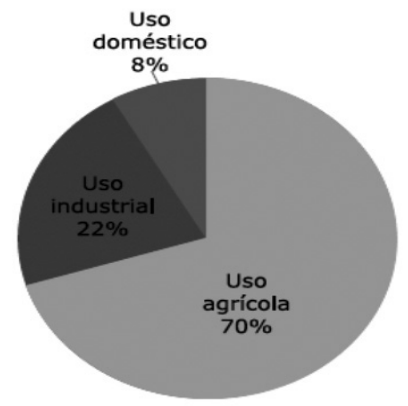

Figura 3: Utilização da água no planeta Fonte: Unesco/2003. forma indireta para a consciencialização ambiental das crianças envolvidas e repetivos pais/familiares, pois, de acordo com Betto (2005) e Pereira (2007), os filhos, em muitos casos, herdam os impulsos consumistas dos pais e do ambiente em que convivem, incluindo a atividades desenvolvidas pela família, em casa. Ora, envolvendo a família em reflexões de natureza ambiental, será de esperar que todos os envolvidos acabem por ser positivamente influenciados pelo processo. Com efeito, processos desta natureza podem começar com o controle dos consumos domésticos levados a cabo pela criança, podendo vir a ser modificados pelos pais, se sensibilizados pelos seus filhos, enquanto, simultaneamente, contribuem como agentes ativos nas suas aprendizagens.

Para facilitar o cálculo da quantidade de água gasta diariamente por cada aluno, tarefa que teria de resolver em casa, foi- Ihe fornecido o quadro 1, contendo os valores de referência para consumos de 


\begin{tabular}{|l|c|}
\multicolumn{1}{|c|}{ Actividade } & $\begin{array}{c}\text { Volume (em } \\
\text { litros) }\end{array}$ \\
\hline 1 descarga do autoclismo & 6 a 16 \\
\hline 1 minuto de banho de chuveiro & 4 a 15 \\
\hline 1 lavagem de mãos & 3 a 5 \\
\hline 1 lavagem com maquina de lavar & 120 a 150 \\
\hline 1 lavagem de louça à mão & 20 e 25 \\
\hline Escovar os dentes com água & 10 a 15 \\
\hline corrente & 80 a 100 \\
\hline Lavagem do automóvel &
\end{tabular}

Quadro 1: Uso doméstico de água por atividade ou equipamento

água em diferentes atividades e equipamentos domésticos, o qual foi devidamente explorado em sala de aula.

As questões II e III parece terem despertado a curiosidade aos alunos, uma vez que todos as realizaram, fazendo as investiga-

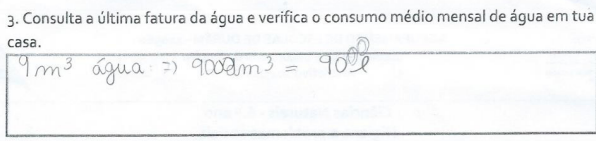

Figura 5: Resposta de um aluno sem NEE a uma atividade proposta

ções necessárias para que fosse possível responder às questões-problema formuladas. Algumas das respostas fornecidas pelos alunos sem NEE podem ser observadas nos registos constantes das figuras 4 e 5 apresentadas a seguir.

As atividades para os alunos com NEE foram adaptadas ao seu desenvolvimento cognitivo, conforme se pode constatar da análise da figura 6 , pois, como referem (GIASSI, et all, 2016), as atividades práticas, reflexivas e materiais didáticos necessários ao desenvolvimento das atividades deverão ser elaborados de acordo com a

\section{Questão-problema II: Que quantidade de água gastas por dia?}

1. Ao longo de um dia, regista no quadro os usos da água em tua casa.

Figura 4: Resposta de um aluno sem NEE à Questãoproblema II

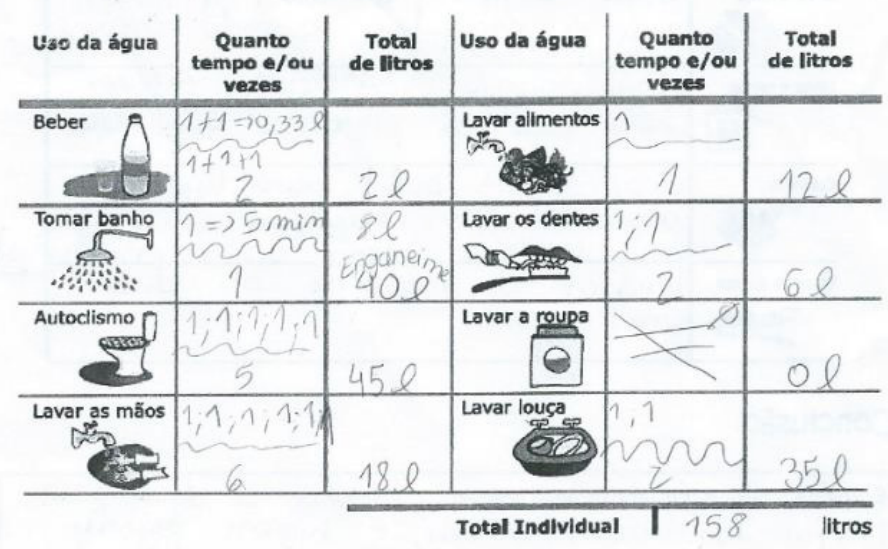

2. Que quantidade de água que gastas numa semana? E num mês?

$158 \times 7=1106 \ell$
$158 \times 30=4740 \ell$




\section{Questão-problema II: Que quantidade de água gastas por dia?}

1. Durante o dia de amanhā, regista as atividades em que gastaste água. Vai assinalando a contagem com traços.

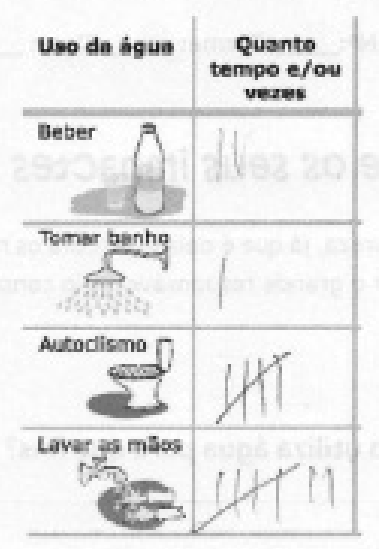

faixa etária dos envolvidos, bem como o seu perfil de funcionalidade.

Todavia, foram mantidas as propostas de componente investigativa presente na atividade dos demais alunos

A Questão-problema III: Como podes diminuir a consumo doméstico de água?, foi realizada em grupo, com todos os alunos, sendo de seguida apresentada à turma. Os alunos com CEI não conseguiram perceber como "colocar uma garrafa cheia

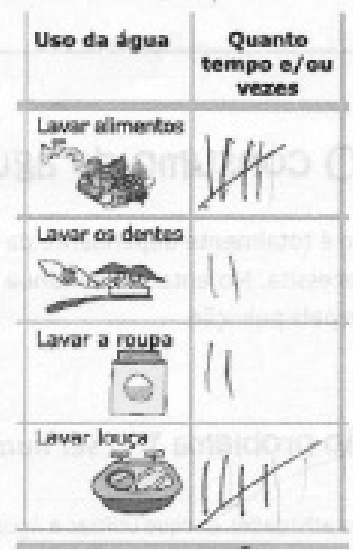
apresentado na figura 7 .
Figura 6: Resposta de um aluno com NEE e grelha de registro adaptada

de água no reservatório do autoclismo" pode contribuir para reduzir o consumo de água; face a essa dificuldade, não assinalaram essa opção, como se pode verificar através da análise do registo efetuado,

Na questão problema III "como podes diminuir o consumo doméstico e água?", é possível perceber que, de forma geral, os alunos sem NEE revelaram saber como proceder de forma a contribuir para essa redução. Estes alunos conseguem referir

Questão-problema III: Como podes diminuir o consumo doméstico de água?

Assinala com $X$ as opçōes que diminuem o consumo de água.

$\underline{X}$ Regular o fluxo de tomeiras e chuveiros.

—Deitar lixo para a sanita.

$\underline{X}$ Reparar equipamentos com fugas de água.

- Tomar banho na banheira.

Figura 7: Resposta de X Fechar a torneira enquanto lavo os dentes.

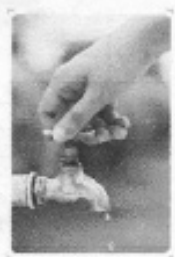
um aluno com NEE $\Longrightarrow$ Colocar uma garrafa cheia de água no reservatório do autoclismo. 
Figura 8: Resposta de um aluno sem NEE
Questão-problema III: Como podes diminuir o consumo doméstico de água?

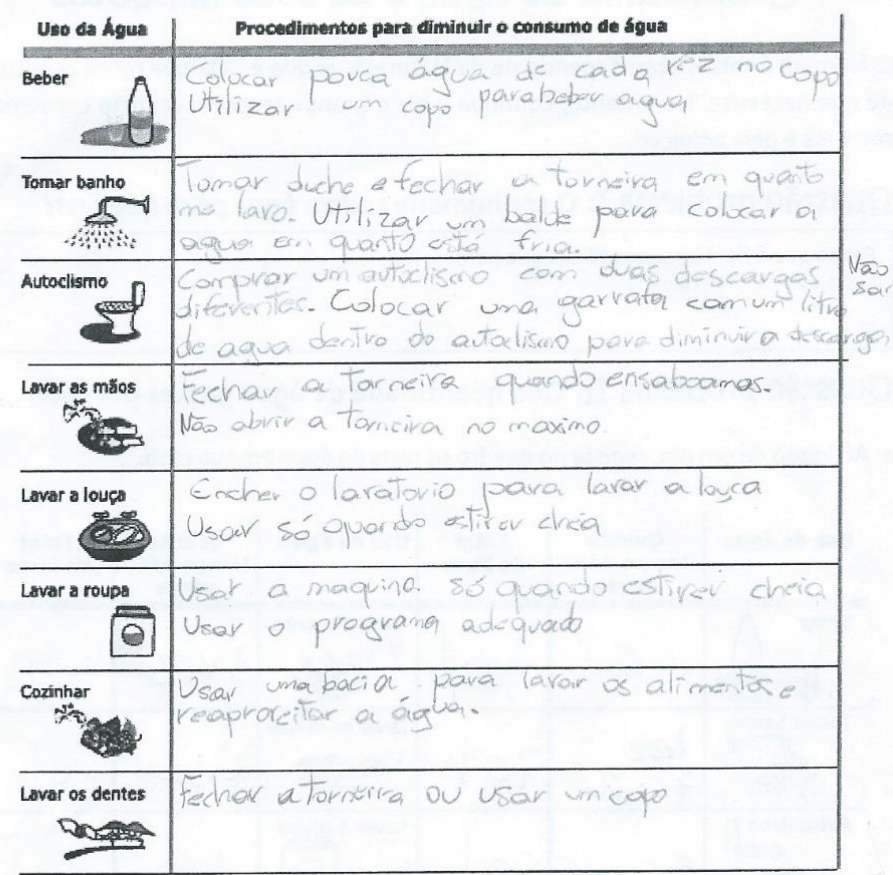

algumas alternativas tecnológicas para minimizar os consumos, como adquirir autoclismos com duas descargas, conforme se pode constatar na figura 8 , na página seguinte.

O trabalho desenvolvido com todos os alunos, incluindo os que têm NEE, reforça a importância da escola e "do papel da educação na compreensão das questões ambientais, que usando ou não o adjetivo ambiental, proporcione nas escolas espaços de sensibilização e capacitação de alunos para uma tomada de consciência e ações concretas, aquisição de conhecimentos que permitam sua integração com a comunidade e a compreensão crítica da complexidade do mundo contemporâneo" (GIAssı, et all, 2016, p. 28). A criança só aprende aquilo que vive concretamente. Para isso podem e devem ser exploradas situações concernentes às atividades da vida diária para que os alunos com NEE desenvolvam a sua autonomia e, enquanto cidadãos mais informados, possam dar o seu contributo, também no que respeita às questões ambientais, considerando "um processo num viés mais problematizador direcionado para as questões mais próximas do contexto de vida dos participantes" (GIASsI, et all, 2016, p. 29). É importante que ela faça suas próprias descobertas através da manipulação, exploração do ambiente físico-social, como sucedeu na 
tarefa em que os alunos tiveram de pesquisar, em suas casas, os consumos de água efetuados por si e respetiva família.

Ao proporcionar a crianças com NEE exploração de atividades relacionadas com o seu quotidiano, "a sociedade ganha, pois teremos cidadãos mais preparados para enfrentar os desafios da sociedade atual cujo maior dilema gira na solução dos problemas ambientais, pois envolvem aspectos econômicos, sociais, recursos naturais, éticos entre outros (Giassi, et all, 2016, p. 31).

Considerando que, conforme anteriormente referido, as atividades descritas foram realizadas na sequência de um curso de formação contínua de professores, tomou-se consciência que o caminho a percorrer neste domínio ainda é longo, mas essencial para a sociedade em geral e para as crianças com NEE mais em particular. Acreditamos que, neste

domínio, a desejável renovação de práticas inovadoras poderá residir na formação e motivação dos professores, podendo ser a sua formação contínua um catalisador de mudança já que os mesmos relatam "que nas escolas, muitas vezes lhes é solicitado que tratem de temas ambientais, que desenvolvam projetos de Educação Ambiental com seus alunos e que nem sempre sentem-se preparados para isso" (GIASSI, et all, 2016, p. 29).

A importância da abordagem das temáticas ambientais na formação de professo- res que trabalham com alunos com NEE é tanto mais importante quanto SAUVÉ (s/d) defende que o ideal seria que a compreensão dos processos educativos considerasse uma visão complementar do ambiente, de uma forma cumulativa, através de uma cuidadosa intervenção, ou preferencialmente, utilizando um enfoque pedagógico integrado. Até porque a cada dia que passa, a questão ambiental tem sido considerada prioritária no sentido de ser trabalhada com toda sociedade e, principalmente, nas escolas, pois "as crianças bem informadas sobre os problemas ambientais vão ser adultas mais preocupadas com o meio ambiente, além do que elas vão ser transmissoras dos conhecimentos que obtiveram na escola sobre as questões ambientais em sua casa, família e vizinhos" (Medeiros, et al, 2008, p. 2). Pretendendo-se que a escola seja efetivamente inclusiva, estas preocupações e desígnios deverão, estar continuamente presentes na formação dos seus professores e nas práticas letivas de Todos os alunos.

\section{Referencias bibliográficas}

BARCELOS, V. (2009). Octávio Paz - Da Ecologia Global à Educação Ambiental na Escola. Lisboa: Instituto Piaget.

BETTO, F. (2005). A publicidade infantil deve ser discutida em sala de aula. Portal Aprendiz. Rio de Janeiro, 22 de junho de 2012. Disponível em: <http://portal.aprendiz.uol.com. br/2012/06/22/frei-betto-\%E2\%80\%9Capublicidade-infantil-deveria-ser-discutidaem-sala-de-aula\%E2\%80\%9D/>. Acedido em 16 de março de 2015. 
FLANNERY, T. (2008). O Clima está nas nossas mãos - história do aquecimento global. Cruz Quebrada: Estrela Polar.

GIASSI, M. G.; DAJORI, J. F.; MACHADO, A. C.; MARTINS, M. C. (2016). Ambiente e Cidadania: educação Ambiental nas escolas. Revista de Extensão, Criciúma/SC, v. 1, n. 1.

GONÇALVES, F.; PEREIRA, R.; AZEITEIRO, U. M. M.; PEREIRA, M. J. V. (2007). Atividades Práticas em Ciências e Educação Ambiental. Lisboa: Instituto Piaget.

MARTINS, I. P., VEIGA, L., TEIXEIRA, F., TENREIRO-VIEIRA, C., VIEIRA, R., RODRIGUES, A. V. e COUCEIRO, F. (2006). Educação em Ciências e Ensino Experimental no $1^{\circ} \mathrm{Ciclo}$ EB. Formação de Professores. Lisboa: Ministério da Educação.

MARTINS, I. P., VEIGA, L., TEIXEIRA, F., TENREIRO-VIEIRA, C., VIEIRA, R., RODRIGUES, A. V. e COUCEIRO, F. (2010). Sustentabilidade na Terra - caderno de registos para crianças. Lisboa: Ministério da Educação.

MARTINS, I. P., VEIGA, L., TEIXEIRA, F., TENREIRO-VIEIRA, C., VIEIRA, R., RODRIGUES, A. V. e COUCEIRO, F. (2010). Sustentabilidade na Terra - guião didático para professores. Lisboa: Ministério da Educação.
MEDEIROS, A. B.; MENDONÇA, M. J. S. L.; SOUSA, G. L. de; OLIVEIRA, I. P. (2011). A Importância da educação ambiental na escola nas séries iniciais. Revista Faculdade Montes Belos, v. 4, n. 1.

PENTEADO, H. D. (2010). Meio Ambiente e Formação de Professores. São Paulo: Cortez Editora.

PEREIRA, L. F. (2007). Que infância estamos construindo? Folha de São Paulo, São Paulo, 12 out. 2007. Disponível em: $<$ http:// www1.folha.uol.com.br/fsp/opiniao/fz1210200709.htm>. Acedido em 16 março de 2017.

PEREIRA, R.; GONÇALVES, F.; AZEITEIRO, U. (2016). Atividades Práticas em Ciências e Educação Ambiental - II. Lisboa: Instituto Piaget.

SAPELLI, M. L. S.; FREITAS, L. C.; CALDART, R. S. (2016). Caminhos para transformação da escola 3. São Paulo: Editora Expressão Popular.

SAUVÉ, L. Educação ambiental e desenvolvimento sustentável: uma análise complexa. Disponivel em www.arvore. com.br. Acedido em 9 de setembro de 2017. 